\title{
APLIKASI METODE POLINOM NEWTONGREGORY MAJU DAN POLINOM NEWTON GREGORY MUNDUR DALAM MEMPREDIKSI BANYAKNYA PENDUDUK SULAWESI TENGAH
}

\author{
G. A. Pratiwi ${ }^{1}$, A. I. Jaya ${ }^{2}$, dan R. Ratianingsih ${ }^{3}$ \\ 1,2,3 Program Studi Matematika Jurusan Matematika \\ Fakultas Matematika dan IImu Pengetahuan Alam Universitas Tadulako \\ Jalan Sukarno-Hatta Km. 9 Palu 94118, Indonesia \\ 1'gitapratiwi453@gmail.com, 2Jayaindraagus@gmail.com, ${ }^{3}$ ratianingsih@yahoo.com
}

\begin{abstract}
Population census, that is conducted every 10 years, is an overall process of collecting, processing, presentation and assessment of population data. This study uses Polinom Newton Gregory Forward and Newton Gregory Backward to predict the number of residents in the Central Sulawesi each year in the period of 1980 to 2010. The problem of this research is "How to predict a population of Central Sulawesi by using Polinom Newton Gregory Forward and Polinom Newton Gregory Backward and which method is more accurate between these two methods in predicting the population of Central Sulawesi". Source of data used are secondary data and the type of data used in this research is quantitative data. The results shows that the prediction by using Polinom Newton Gregory Forward is closer to the prediction data from the Central Bereau of Statistics in compare to another one by using Polinom Newton Gregory Backward, whose comparison accuracy of the two methods can be seen in the value of the relative error. In the study using Polinom Newton Gregory Forward the obtained Relative Error is $\sum \varepsilon_{\mathrm{R}}=0,392737492$ while the research using Polinom Newton Gregory Backward the Relative Error $\sum \varepsilon_{R}=1,250680497$.
\end{abstract}

Keyword : Polinom Newton Gregory Forward, Polinom Newton Gregory Backward, Population Census, Prediction of Population, Relative Error.

\section{ABSTRAK}

Sensus Penduduk, yang dilaksanakan 10 tahun sekali, merupakan suatu proses keseluruhan dari pengumpulan, pengolahan, penyajian dan penilaian data penduduk. Penelitian ini mengg"Bagaimana Prediksi Banyaknya Penduduk Sulawesi Tengah dengan Menggunakan metode Polinom Newton Gregory Maju dan Polinom Newton Gregory Mundur serta Metode mana yang lebih akurat diantara Metode Polinom Newton Gregory Maju dan Polinom Newton Gregory Mundur dalam memprediksi Banyaknya penduduk Sulawesi Tengah". Sumber data yang digunakan adalah data sekunder dan jenis data yang digunakan dalam unakan metode polinom newton Gregory maju dan polinom newton Gregory mundur untuk memprediksi banyaknya penduduk Sulawesi tengah disetiap tahun pada periode 1980 sampai dengan 2010. Rumusan masalah dalam penelitian ini adalah penelitian ini adalah data kuantitatif. Hasil penelitian menunjukan bahwa prediksi dengan menggunakan metode polinom Newton Gregory Maju lebih mendekati data prediksi dari Badan Pusat Statistik di bandingkan prediksi dengan menggunakan metode polinom Newton Gregory Mundur, yang mana perbandingan keakuratan dari kedua 
metode tersebut dapat dilihat berdasarkan perolehan galat relatifnya (error). Pada penelitian dengan menggunakan metode polinom Newton Gregory Maju diperoleh Galat Relatif $\sum \varepsilon_{R}=0,392737492$, Sedangkan penelitian dengan menggunakan metode polinom Newton Gregory Mundur diperoleh GalatRelatif $\sum \varepsilon_{R}=1,250680497$.

Kata Kunci : Polinom Newton Gregory Maju, Polinom Newton Gregory Mundur, Sensus Penduduk, Prediks i Penduduk, Galat Relatif.

\section{PENDAHULUAN}

\subsection{Latar Belakang}

Pelaksanaan sensus yang dilakukan oleh Badan Pusat Statistik (BPS) Provinsi Sulawesi Tengah dilaksanakan dalam kurung waktu 10 tahun sekali melalui sensus penduduk. Prediksi penduduk pada tahun berikutnya dalam tiap periode sensus perlu dilakukan untuk mengetahui selisih pertambahan penduduk pada tahun tersebut (BPS, 2003). Polinom Newton Gregory merupakan kasus khusus dari Polinom Newton untuk titik-titik yang berjarak sama, dimana rumus polinom Newtonnya lebih sederhana. Selain itu, tabel selisih terbaginya pun lebih mudah dibentuk. Ada dua macam tabel selisih, yaitu tabel selisih maju (forward difference) dan tabel selisih mundur (backward difference), Oleh Karena itu terdapat dua macam polinom Newton-Gregory, yaitu polinom Newton-Gregory Maju dan polinom Newton-Gregory Mundur (Munir, R., 2003).

Peneliti tertarik untuk mengkaji banyaknya penduduk Sulawesi Tengah diantara empat periode sensus, dengan menggunakan metode Polinom Newton Gregory Maju dan Polinom Newton Gregory Mundur. Selanjutnya Untuk melihat perbandingan kelayakan atau akurasi hasil prediksi ini, akan dikaji taksiran galat dari kedua Metode tersebut. Sedangkan untuk mendapatkan hasil perhitungan dengan lebih cepat akan dibuatkan program komputernya. Harapan peneliti adalah agar dapat dijadikan sebagai aplikasi alternatif bagi Badan Pusat Statistik (BPS) untuk memprediksi banyaknya penduduk pada tahun diantara periode sensus.

Berdasarkan latar belakang tersebut peneliti mengangkat sebuah masalah yang kemudian akan dijadikan sebuah skripsi dengan judul : "Aplikasi Metode Polinom Newton Gregory Maju dan Polinom Newton Gregory Mundur Dalam Memprediksi Banyaknya Penduduk Sulawesi Tengah".

\subsection{Rumusan Masalah}

Berdasarkan latar belakang tersebut, permasalahan penelitian ini adalah :

1. Bagaimana prediksi banyaknya penduduk Sulawesi Tengah dengan menggunakan metode Polinom Newton Gregory Maju dan Polinom Newton Gregory Mundur? 
2. Metode mana yang lebih akurat diantara Metode Polinom Newton Gregory Maju dan Polinom Newton Gregory Mundur dalam memprediksi Banyaknya penduduk Sulawesi Tengah?

\section{METODE PENELITIAN}

Langkah-langkah yang dilakukan dalam penelitian ini yaitu :

1. Memulai penelitian.

2. Melakukan pengambilan data pada Badan Pusat Statistik Sulawesi Tengah.

3. Memodelkan Polinom Newton Gregory Maju dan Polinom Newton Gregory Mundur.

4. Melakukan prediksi banyaknya penduduk sulawesi tengah secara manual.

5. Melakukan prediksi banyaknya penduduk sulawesi tengah dengan program komputer.

6. Perhitungan Galat Relatif.

7. Menyimpulkan hasil penelitian.

8. Selesai.

\section{HASIL DAN PEMBAHASAN}

\subsection{Hasil Penelitian}

Prediksi Polinom Newton Gregory Maju diselesaikan menggunakan persamaan berikut $: P_{4}(x)=f_{0}+\frac{s}{1 !} \Delta f_{0}+\frac{s(s-1)}{2 !} \Delta^{2} f_{0}+\frac{s(s-1)(s-2)}{3 !} \Delta^{3} f_{0}$ dimana $\Delta f_{0}, \Delta^{2} f_{0}, \Delta^{3} f_{0}$ ditentukan melalui tabel beda terbagi Newton Gregory Maju dengan menggunakan Data Sensus penduduk Sulawesi Tengah dengan jarak sensus 10 tahun, Data tersebut dapat dilihat pada lampiran 1 (Tabel 1.3 Data Sensus Penduduk). Sedangkan untuk Polinom Newton Gregory Mundur menggunakan persamaan Berikut: $Q_{4}(x)=f_{0}+\frac{s}{1 !} \nabla f_{0}+\frac{s(s+1)}{2 !} \nabla^{2} f_{0}+\frac{s(s+1)(s+2)}{3 !} \nabla^{3} f_{0}$ dimana $\nabla f_{0}, \nabla^{2} f_{0}, \nabla^{3} f_{0}$ ditentukan melalui tabel beda terbagi Newton Gregory Mundur, Sama halnya dengan polinom newton gregory maju, Polinom Newton Gregory Mundur juga menggunakan Data Sensus penduduk Sulawesi Tengah dengan jarak sensus 10 tahun, yang mana Data Sensus Penduduk tersebut diperoleh dari Badan Pusat Statistik Sulawesi Tengah. Pada penelitian ini digunakan Persamaan Galat Relatif untuk mengetahui seberapa besar error yang dihasilkan dengan mensubtitusikan Hasil prediksi dari masing-masing metode yaitu, nilai sejati (Data Prediksi Banyaknya penduduk oleh BPS pada tahun 1981-2009/Lampiran 2 Tabel 1.4) serta Nilai Hampiran (Data Prediksi dengan menggunakan polinom newton gregory maju dan gregory mundur) pada persamaan berikut: Misalkan $\hat{a}$ adalah nilai hampiran terhadap nilai sejati $a$, maka selisi antara nilai sejati dan nilai hampiran dapat dinyatakan dalam persamaan : $\varepsilon=a-\hat{a}$. Pada penelitian ini, tanda (galat positf dan negatif) tidak dipertimbangkan, sehingga galat mutlak dapat didefinisikan sebagai $|\varepsilon|=|a-\hat{a}|$, kemudian untuk mencegah kemungkinan nilai galat $\varepsilon$ bernilai besar maka harus dinormalkan terhadap nilai sejatinya $\varepsilon_{R}=\frac{\varepsilon}{a}$ yang disebut Galat Relatif. Berikut Data prediksi dari kedua metode Polinom Newton Gregory Maju dan Polinom Newton Gregory Mundur, Data tersebut 
telah melalui proses pembulatan karena menyangkut jiwa seseorang. Data prediksi dari kedua metode tersebut disajikan pada Tabel 1 dan Tabel 2.

Tabel 1 : Prediksi banyaknya penduduk Sulawesi Tengah beserta Galat Relatif dengan menggunakan metode polinom Newton Gregory Maju.

\begin{tabular}{|c|c|c|c|c|c|}
\hline Tahun & $\begin{array}{c}\text { Prediksi } \\
\text { Banyaknya } \\
\text { Penduduk } \\
\text { (Jiwa) }\end{array}$ & $\begin{array}{c}\text { Galat Relatif } \\
\text { Polinom Newton } \\
\text { Gregory Maju }\end{array}$ & Tahun & $\begin{array}{l}\text { Prediksi } \\
\text { Banyaknya } \\
\text { Penduduk } \\
\text { (Jiwa) }\end{array}$ & $\begin{array}{c}\text { Galat Relatif } \\
\text { Polinom } \\
\text { Newton } \\
\text { Gregory Maju } \\
\left(\varepsilon_{R}\right)\end{array}$ \\
\hline 1981 & 1328485 & 0,01014455 & 1996 & 2269804 & 0,004465699 \\
\hline 1982 & 1368202 & 0,016672416 & 1997 & 2316503 & 0,005972059 \\
\hline 1983 & 1408737 & 0,023405893 & 1998 & 2363000 & 0,007694581 \\
\hline 1984 & 1450043 & 0,030331015 & 1999 & 2409246 & 0,009731615 \\
\hline 1985 & 1492070 & 0,037249968 & 2001 & 1756662 & 0,001568844 \\
\hline 1986 & 1534770 & 0,043637836 & 2002 & 1802378 & 0,002730135 \\
\hline 1987 & 1578095 & 0,050198616 & 2003 & 1848427 & 0,003483706 \\
\hline 1988 & 1621995 & 0,056979651 & 2004 & 1894760 & 0,003830102 \\
\hline 1989 & 1666422 & 0,064018198 & 2005 & 1941327 & 0,003770944 \\
\hline 1991 & 1988082 & 0,000249274 & 2006 & 2455192 & 0,003558163 \\
\hline 1992 & 2034974 & 0,000677534 & 2007 & 2500791 & 0,003027382 \\
\hline 1993 & 2081956 & 0,001174214 & 2008 & 2545992 & 0,00209709 \\
\hline 1994 & 2128978 & 0,00212766 & 2009 & 2590747 & 0,000770642 \\
\hline 1995 & 2222951 & 0,003169705 & \multicolumn{3}{|c|}{$\begin{array}{c}\text { Total } \\
\sum \varepsilon_{R}=\mathbf{0 , 3 9 2 7 3 7 4 9 2}\end{array}$} \\
\hline
\end{tabular}

Tabel 2 : Prediksi banyaknya penduduk Sulawesi Tengah beserta galat relative dengan menggunakan metode polinom Newton Gregory Mundur

\begin{tabular}{|c|c|c|c|c|c|}
\hline Tahun & $\begin{array}{c}\text { Prediksi } \\
\text { Banyaknya } \\
\text { Penduduk } \\
\text { (Jiwa) }\end{array}$ & $\begin{array}{c}\text { Galat Relatif } \\
\text { Polinom Newton } \\
\text { Gregory mundur }\end{array}$ & Tahun & $\begin{array}{c}\text { Banyaknya } \\
\text { Penduduk } \\
\text { (Jiwa) }\end{array}$ & $\begin{array}{c}\text { Galat Relatif } \\
\text { Polinom } \\
\text { Newton } \\
\text { Gregory } \\
\text { mundur }\left(\boldsymbol{\varepsilon}_{\boldsymbol{R}}\right)\end{array}$ \\
\hline 1981 & 1332296 & 0,00730497 & 1996 & 1932363 & 0,032367051 \\
\hline 1982 & 1374851 & 0,011893776 & 1997 & 1967506 & 0,038928292 \\
\hline 1983 & 1417253 & 0,017502253 & 1998 & 2001767 & 0,045914399 \\
\hline 1984 & 1459453 & 0,024038384 & 1999 & 2035096 & 0,053399693 \\
\hline
\end{tabular}




\begin{tabular}{|l|l|l|l|l|l|}
\hline 1985 & 1501401 & 0,031229191 & 2001 & 2098765 & 0,054384179 \\
\hline 1986 & 1543050 & 0,038478315 & 2002 & 2129007 & 0,059469682 \\
\hline 1987 & 1584351 & 0,046433343 & 2003 & 2158123 & 0,065124774 \\
\hline 1988 & 1625254 & 0,055084884 & 2004 & 2186064 & 0,071334385 \\
\hline 1989 & 1665713 & 0,064416423 & 2005 & 2212781 & 0,078082822 \\
\hline 1991 & 1745098 & 0,006830573 & 2006 & 2238227 & 0,085126142 \\
\hline 1992 & 1783928 & 0,010907075 & 2007 & 2262351 & 0,092607098 \\
\hline 1993 & 1856713 & 0,003303253 & 2008 & 2285107 & 0,100586697 \\
\hline 1994 & 1859620 & 0,020634085 & 2009 & 2306444 & 0,109051775 \\
\hline 1995 & 1896384 & 0,026246983 & \multicolumn{3}{|c|}{$\begin{array}{c}\text { Total } \\
\end{array}$} \\
\hline
\end{tabular}

\subsection{Pembahasan}

Prediksi banyaknya penduduk Sulawesi Tengah menggunakan metode polinom Newton Gregory Maju dan polinom Newton Gregory Mundur, ditampilkan pada Tabel 1 dan Tabel 2 dapat dilihat bahwa akurasi prediksi banyaknya penduduk Sulawesi Tengah dengan menggunakan dua metode, yaitu metode Polinom Newton Gregory Maju dan Polinom Newton Gregory Mundur, tidak memberikan hasil yang sama. Perolehan galat total metode Newton gregory maju sebesar $\sum \varepsilon_{\mathbf{R}}=0,392737492$ lebih baik, Sedangkan untuk metode polinom Newton gregory mundur diperoleh nilai Galat total sebesar $\sum \varepsilon_{R}=1,250680497$. Dengan demikian metode polinom Newton Gregory Maju memiliki akurasi yang lebih baik. Prediksi kedua metode tersebut ditampilkan pula dalam bentuk grafik sebagai berikut :

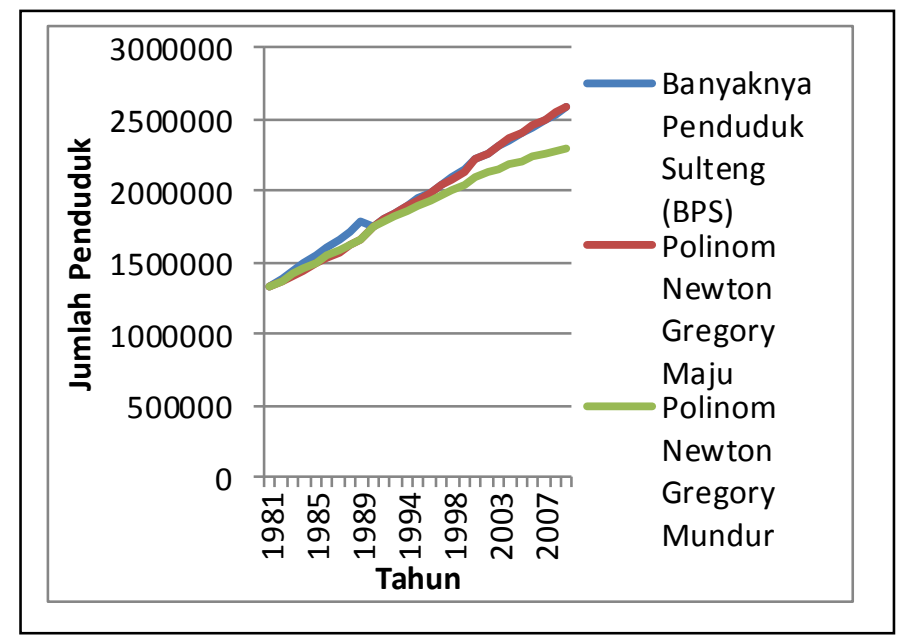

Gambar 1 : Grafik Perbandingan Hasil Prediksi Metode Polinom Newton Gregory Maju, Mundur dan Data BPS 
Grafik pada Gambar 1 menunjukan perbandingan hasil prediksi dari Badan Pusat Statistik dengan hasil prediksi menggunakan metode polinom Newton gregory maju dan polinom Newton gregory mundur. Garis biru pada grafik tersebut merupakan garis yang menunjukan banyaknya penduduk Sulawesi Tengah melalui sensus yang dilaksanakan oleh Badan Pusat Statistik (BPS), Garis merah pada grafik tersebut menunjukan hasil prediksi dengan menggunakan metode polinom Newton Gregory Maju sedangkan garis ber warna hijau adalah garis yang menunjukan hasil prediksi dengan menggunakan metode polinom Newton Gregory Mundur. Pada grafik tersebut dapat dilihat bahwa pada interval tahun 1981 1990 prediksi dengan kedua metode polinom Newton Gregory Maju dan polinom Newton Gregory Mundur nampak berhimpitan, Selanjutnya pada interval tahun 1991-2007 prediksi dengan metode polinom Newton Gregory Maju nampak berhimpit dengan hasil prediksi dari Badan Pusat Statistik, Sedangkan prediksi dengan menggunakan metode polinom Newton Gregory Mundur nampak menonjolkan penyimpangan pada interval tahun tersebut.

\section{KESIMPULAN}

Dengan melihat hasil penelitian yang telah dibahas dalam bab sebelumnya, dapat ditarik kesimpulan sebagai berikut:

1. Perolehan nilai total galat relatif metode Newton gregory maju sebesar $\sum \varepsilon_{\mathbf{R}}=0,392737492$, Sedangkan untuk metode polinom Newton gregory mundur diperoleh nilai galat total sebesar $\sum \varepsilon_{R}=1,250680497$. Prediksi kedua metode tersebut ditampilkan pula dalam bentuk grafik (1.1) dalam pokok bahasan bab sebelumnya, Pada grafik tersebut dapat dilihat bahwa pada interval tahun 1981-1990 prediksi dengan kedua metode polinom Newton Gregory Maju dan polinom Newton Gregory Mundur nam pak berhimpitan, Selanjutnya pada interval tahun 1991 2007 prediksi dengan metode polinom Newton Gregory Maju nampak berhimpit dengan hasil prediksi dari Badan Pusat Statistik, Sedangkan prediksi dengan menggunakan metode polinom Newton Gregory Mundur nampak menonjolkan penyimpangan pada interval tahun tersebut. Dengan demikian metode polinom Newton Gregory Maju memiliki akurasi yang lebih baik dibandingkan metode polinom Newton Gregory Mundur.

2. Berikut ini data hasil prediksi penduduk Sulawesi tengah dari Badan Pusat Statistik dan hasil prediksi dengan menggunakan metode polinom newton Grogory Maju dan polinom newton Gregory mundur, dan selisi jiwa antara data dari Badan Pusat Statstik dibandingan dengan data hasil prediksi menggunakan Metode polinom newton Gregory Maju dan polinom newton Gregory Mundur beserta Galat Relatif nya. 


\section{DAFTAR PUSTAKA}

[1] Badan Pusat Statistik, 2003, Sensus penduduk, (http://sensuspenduduk.blogspot. com), diakses 08 november 2014.

[2] Herwanto, E.,2010, Prediksi Banyaknya Penduduk Sulawesi Tengah Dengan Menggunakan Metode Polinom Newton Gregory Maju, Fakultas Matematika dan IImu Pengetahuan Alam Universitas Tadulako, Sulawesi tengah, Palu.

[3] Mantra, B.I.,2003, Demografi umum, Yogyakarta, Yogyakarta.

[4] Munir, R., 2003, Metode Numerik, Informatika Bandung, Bandung.

[5] Nasution, A. Dan Zakaria, H., 2001, Metode Numerik dalam IImu Rekayasa Sipil, ITB, Bandung.

[6] Suarga, 2006, Algoritma Pemrograman, Andi Offset, Yogyakarta.

[7] Susila, I.N., 1993, Dasar-dasarMetode Numerik, Departemen Pendidikan dan Kebudayaan, Bandung.

[8] Sutedjo, B. Dan Michael, A.N., 1997, Algoritma dan Teknik Pemrograman, Andi Offset, Yogyakarta. 